\title{
Hubungan Tingkat Pengetahuan Dokter Muda Tentang Jenis Malpraktik Dengan Kurikulum Hukum Kesehatan Pada Stase Forensik Medikolegal
}

\author{
Ali Taufan \\ Laboratorium Forensik Medikolegal \\ Fakultas Kedokteran Universitas Jenderal Achmad Yani \\ Email: ajat68738@gmail.com
}

\begin{abstract}
At present the law is part of the world of medicine. The law will guarantee legal certainty that guarantees the rights and obligations of doctors and patients. To increase doctors' knowledge regarding malpractice material regarding malpractice given to the medicolegal forensic stage. This study aims to determine the relationship between the level of knowledge of young doctors about malpractice based on the force and the medicolegal forensic stage. The research design used was descriptive analytic method using Cross Sectional study. The sample in this study was taken using simple random sampling technique. Hypothesis 0 which is a significant relationship between knowledge about medical malpractice and students who have passed the forensic stage. Correlation has a low positive correlation that is directly proportional to the increase in number. Second data analysis about knowledge about reporting procedures The alternative hypothesis is correct. This is shown because it is not meaningful because $\mathrm{p}>0.05$.
\end{abstract}

Keyword: Phisician, Forensic Medicolegal, Malpractice

\begin{abstract}
Abstrak. Saat ini hukum menjadi bagian dari dunia kedokteran. Hukum akan menjamin kepastian hukum yang menjamin hak dan kewajiban dokter dan pasien. Untuk meningkatkan pengetahuan dokter mengenai malpraktik materi mengenai malpraktik yang di berikan pada stase forensik medikolegal. Penelitian ini bertujuan untuk mengetahui hubungan tingkat pengetahuan dokter muda tentang malpraktik berdasarkan angkatan dan stase forensik medikolegal. Rancangan penelitian yang digunakan adalah metode deskriptif analitik menggunakan studi Cross Sectional. Sampel dalam penelitian ini diambil dengan menggunakan teknik simple random sampling. Hipotesis 0 yang merupakan terdapat hubungan signifikan antara pengetahuan mengenai malpraktik kedokteran dengan mahasiswa yang telah melewati stase forensic medikolegal. Korelasi memiliki korelasi positif rendah yakni berbanding lurus dengan kenaikan jumlah. Analisis data kedua tentang pengetahuan mengenai prosedur pelaporan Hipotesis alternatif adalah benar. Hal ini ditunjukkan karena tidak bermakna karena p>0,05.
\end{abstract}

Kata Kunci: Dokter Muda, Forensik Medikolegal, Malprkatik

\section{A. PENDAHULUAN}

Praktek kedokteran sangat dekat dengan hukum. Dahulu dunia kedokteran seakan berada pada kutub yang berbeda dengan dunia hukum. Namun sejalan dengan perkembangan jaman hukum menjadi bagisan yang tidak terpisahkan dari dunia kedokteran. Sebenarnya hukum sangat baik bagi kedokteran karena akan menjamin kepastian hukum antara dokter dan pasien. Namun disisi lain timbul konsekwensi yang harus dihadapi bila ada ketidakpuasan pada sisi pasein maka pasien bisa menuntut dokter. Masyarakat sudah menyadari hak-haknya sebagai pasien. Masalah yang sering timbul karena sifat paternalistik dokter dengan autonomi pasien. ${ }^{1,2,3}$ Dokter dikawal dengan adanya kode etik kedokteran serta Undang-undang yang selalu menjadi panduan dalam berpraktik. Pasien berhak mendapatkan pelayanan yang terstandar mulai dari awal perjanjian terapetik sampai dengan terapi. ${ }^{4,5}$

Aturan yang terkait adalah UndangUndang no. 29 tahun 2004 tentang praktik kedokteran mengamanatkan dibentuknya Majelis Kehormatan Disiplin Kedokteran Indonesia (MKDKI) dan Majelis Kehormatan 
Disiplin Kedokteran Indonesia ditingkat Provinsi (MKDKI-P) sebagai lembaga otonom dan independen sebagai wadah pengaduan dugaan pelanggaran disiplin dokter dari masyarakat. Konsil Lembaga penegakkan etika dan norma kedokteran dibentuklah Majelis Kehormatan Etik Kedokteran (MKEK) yang merupakan suatu badan independen dibawah Ikatan Dokter Indonesia (IDI). ${ }^{6,7,8,9}$

Masih ada kesalahpahaman masyarakat yang menganggap ketidak sembuhan penyakitnya adalah suatu malpraktek. Bila dilihat dari hubungan dokter-pasien bukan hubungan ditujukan pada hasil atau resultaat pelayanan medis, melainkan dari hasil secara maksimal. Maka sepanjang perlakuan medis terhadap pasien telah dilakukan secara benar dan patut menurut Standar Profesi dan Standar Prosedur Operasional dan sesuai kebutuhan medis pasien, tanpa hasil penyembuhan yang diharapkan tidak dapat diketegorikan malpraktik kedokteran. ${ }^{6,10}$

\section{Tinjauan Pustaka}

Definisi malpraktik berarti praktik yang salah dimana seorang dokter tidak sesuai dengan standar praktik kedokteran. ${ }^{16.17}$ Istilah Malpraktik dapat diartikan kegagalan seorang dokter dalam melakukan praktik yang sesuai dengan kaidah-kaidah yang benar.$^{15}$ Malpraktik secara luas dapat digunakan dalam profesi lain selain kedokteran. ${ }^{18}$ Seperti halnya insinyur, ahli hukum, dan akuntant. ${ }^{15,18,19}$

Malpraktik murni mempunyai sifat kesengajaan yang hingga dipidanakan karena melakukan yang dilarang oleh peraturan perundang-undangan seperti melakukan abortus tanpa indikasi medis, atau dalam bentuk kelalaian seperti menelantarkan pasien karena lupa, sehingga mengakibatkan penyakit pasien bertambah parah hingga menyebabkan kematian. ${ }^{20}$

Malpraktik medik dapat di ketegorikan dalam ethical malpractice, legal malpractice, malpraktik perdata, malpraktik pidana yaitu terdapat unsur kesengajaan yang memenuhi unsur hukum pidana dan mal praktik administrasi. Pada umumnya, pembedahan tanpa informed consent termasuk penganiayaan. Sifat melawan hukumnya terletak pada tanpa informed consent sehingga jika ada informed consent maka pembedahan sebagai penganiayaan kehilangan sifat melawan hukum. Informed consent merupakan dasar peniadaan pidana, sebagai alasan pembenar, bukan alasan pemaaf. ${ }^{10,20,21,22,23}$ Kealpaan yang menyebabkan luka-luka terdapat dua macam tindak pidana menurut KUHP pasal 360, seseorang karena kealpaannya akan diancam pidana, ${ }^{24}$

Sebagai contoh ketentuan KUHP, setiap tindakan aborsi dengan motif apapun, indikasi apapun dengan cara apapun dan dalam keadaan apapun adalah kejahatan. Namun, dalam hukum kesehatan melalui UU No. 36 Tahun 2009 tentang kesehatan tidak termasuk apabila dapat dilakukan dengan syaratsyarat tertentu, yaitu: atas indikasi medis ${ }^{10,11,22,25,26}$ Malpraktik perdata terjadi apabila terdapat hal-hal yang menyebabkan tidak terpenuhinya isi perjanjian dalam transaksi terapeutik oleh dokter dan pasien. ${ }^{27}$

MKDKI adalah lembaga otonom dan independen yang berwenang untuk menentukan ada tidaknya kesalahan yang dilakukan oleh dokter dan dokter gigi dalam menerapkan disiplin ilmu kedokteran dan kedokteran gigi serta memberikan sanksi apabila terdapat kesalahan atau pelanggaran. Ditingkat daerah terdapat MKDKI-P dibentuk oleh Konsil Kedokteran Indonesia atas usul MKDKI. Kedua lembaga tersebut 
bertanggung jawab secara administratif kepada konsil kedokteran Indonesia. ${ }^{6,28}$ Yuridiksi MKEK adalah untuk meneliti menyidangkat pengaduan dan menjatuhkan sanksi etik bagi dokter yang diadukan sesuai dengan lokasi/tempat terjadinya kasus atau wilayah terdekat terjadinya kasus. ${ }^{29,30}$

Kode etik kedokteran dinyatakan berlaku bagi semua dokter di Indonesia sebagai pedoman perilaku dokter. Kode etik kedokteran terdiri dari pasal yang di bagi menjadi 5 bagian, yaitu: ${ }^{3,4}$ Kode etik kedokteran mengatur tentang etika dokter terhadap orang lain sebagai pasien diri sendiri dan juga teman sejawatnya, apabila terdapat pelanggaran dari kode etik tersebut maka akan di pertimbangkan pengaduan kepada MKEK. 3,26,29,31

Pengetahuan menurut Kamus Besar Bahasa Indonesia (KBBI) adalah, sesuatu yang dapat dimengerti dan dipahami setelah melihat atau dijelaskan. Hal ini menjelaskan bahwa pengetahuan didapatkan ketika kita memahami atau mengerti suatu hal, mengerti mengenai hal-hal ini dapat dilakukan dalam berbagai macam teknik atau metode, misalnya dengan cara melihat, mendengarkan penjelasan, memahami suatu tulisan, dan banyak lagi. ${ }^{8,12,8,13,14}$

\section{B. METODE PENELITIAN}

Hipotesis dalam penelitian ini didapatkan 2 kemungkinan ya itu hipotesis 0 dan hipotesis alternatif.

Ho : Terdapat hubungan tingkat pengetahuan dokter muda tentang jenis malpraktik dengan kurikulum hukum kesehatan pada stase forensik medikolegal.

H1 : Tidak terdapat hubungan tingkat pengetahuan dokter muda tentang jenis malpraktik dengan kurikulum hukum kesehatan pada stase forensik medikolegal

\section{Rancangan Penelitian}

Rancangan penelitian yang digunakan adalah metode deskriptif analitik menggunakan studi Cross Sectional. ${ }^{32}$ Subjek penelitian ini adalah dokter muda Fakultas Kedokteran Universitas Jenderal achmad Yani dengan kriteria inklusi: dokter muda yang sudah mendapatkan kurikulum hukum kesehatan pada stase forensik dan belum mendapatkan kurikulum hukum kesehatan pada stase forensik, dokter muda yang hadir saat pengumpulan data.

Besar sampel pada penelitian ini menggunakan rumus deskriptif kategorik. $^{32,33}$ didapatkan pembulatan jumlah minimal sampel sebanyak 76 orang dari mahasiswa dokter muda. Sampel dalam penelitian ini diambil dengan menggunakan teknik simple random sampling.

Instrumen penelitian/Bahan dan Alat

Instrumen yang digunakan dalam penelitian ini adalah dua buah kuisioner yang terdiri dari 15 pertanyaan untuk kuisioner tentang pengetahuan dokter muda tentang malpraktek mulai dari definisi kategori malpraktik dan 10 pertanyaan untuk mengetahui pengetahuan tentang sistem pelaporan malpraktik.

\section{HASIL DAN PEMBAHASAN}

Penelitian yang dilakukan di RS Dustira pada bulan Februari 2018. Tujuan pada penelitian adalah mengetahui Hubungan Tingkat Pengetahuan Dokter Muda Tentang Jenis Malpraktik Dengan Kurikulum Hukum Kesehatan Pada Stase Forensik Medikolegal. 
Tabel 1. Karakteristik Responden berdasarkan Angkatan dan Stase Forensik Medikolegal

\begin{tabular}{lcc}
\hline \multicolumn{1}{c}{ Variabel } & Jumlah & Persentase (\%) \\
Angkatan & & \\
2012 & 41 & 53,9 \\
2013 & 35 & 46,1 \\
Total & 76 & 100,0 \\
Telah mendapatkan kurikulum & & \\
hukum kesehatan pada Stase & & \\
Forensik Medikolegal & & \\
$\quad$ Sudah & 45 & 59,2 \\
$\quad$ Belum & 31 & 40,8 \\
Total & 76 & 100,0 \\
\hline
\end{tabular}

Berdasarkan kurikulum program pendidikan profesi dokter di Fakultas Kedokteran Universitas Jenderal Achmad Yani Dokter muda harus melewati 14 stase untuk lulus dari jenjang profesi dokter. Salah satunya yaitu bagian forensik medikolegal selama 4 minggu, selama dibagian ini dokter muda diharapkan dapat belajar mengenai ilmu kedokteran kehakiman dan hukum kesehatan. Dalam hukum kesehatan mempelajari tentang malpraktik kedokteran. Angkatan 2012 dan 2013 merupakan mahasiswa adalah angkatan yang menggunakan kurikulum yang sama.

\section{Tabel 2. Case Processing Summary}

\begin{tabular}{|c|c|c|c|c|c|c|}
\hline & \multicolumn{9}{|c|}{ Cases } \\
\cline { 2 - 7 } & \multicolumn{2}{|c|}{ Valid } & \multicolumn{2}{|c|}{ Missing } & \multicolumn{2}{|c|}{ Total } \\
\cline { 2 - 7 } & $\mathrm{N}$ & Percent & $\mathrm{N}$ & Percent & $\mathrm{N}$ & Percent \\
\hline $\begin{array}{c}\text { Tingkat Pengetahuan * Telah } \\
\text { mendapatkan kurikulum } \\
\text { hukum kesehatan } \\
\begin{array}{c}\text { Tingkat Pengetahuan * } \\
\text { Angkatan }\end{array}\end{array}$ & 76 & $100,0 \%$ & 0 & $0,0 \%$ & 76 & $100,0 \%$ \\
\hline
\end{tabular}

Tabel 3. Tingkat Pengetahuan * Telah melewati stase Crosstabulation

\begin{tabular}{|cc|c|c|c|}
\hline \multicolumn{1}{|c|}{ Count } & \multicolumn{2}{c|}{} \\
\cline { 3 - 4 } & & Telah melewati stase & \multirow{2}{*}{ Total } \\
\cline { 3 - 4 } Tingkat Pengetahuan & Baik $>75 \%$ & 16 & 39 & 55 \\
& Cukup 75\%-56\% & 10 & 4 & 14 \\
& Kurang $<56 \%$ & 2 & 5 & 7 \\
Total & & 28 & 48 & 76 \\
\hline
\end{tabular}


Tabel 4. Tingkat Pengetahuan * Angkatan Crosstabulation Count

\begin{tabular}{|rc|c|c|c|}
\hline & & \multicolumn{2}{|c|}{ Angkatan } & \multirow{2}{*}{ Total } \\
\cline { 3 - 4 } & & 2012 & 2013 & Th \\
\hline Tingkat Pengetahuan & Baik >75\% & 29 & 26 & 55 \\
& Cukup 75\%-56\% & 7 & 7 & 14 \\
& Kurang <56\% & 5 & 2 & 7 \\
Total & & 41 & 35 & 76 \\
\hline
\end{tabular}

Tabel 5. Correlations

\begin{tabular}{|c|c|c|c|c|c|}
\hline & & & Angkatan & $\begin{array}{c}\text { Tingkat } \\
\text { Pengetahuan }\end{array}$ & $\begin{array}{l}\text { Telah melewati } \\
\text { stase }\end{array}$ \\
\hline \multirow[t]{3}{*}{$\begin{array}{l}\text { Spearm } \\
\text { an's rho }\end{array}$} & Angkatan & $\begin{array}{c}\text { Correlation Coefficient } \\
\text { Sig. (2-tailed) } \\
\text { N }\end{array}$ & $\begin{array}{c}1,000 \\
\cdot \\
76\end{array}$ & $\begin{array}{c}-, 055 \\
, 635 \\
76\end{array}$ & $\begin{array}{c}-, 279^{*} \\
, 015 \\
76\end{array}$ \\
\hline & $\begin{array}{c}\text { Tingkat } \\
\text { Pengetahuan }\end{array}$ & $\begin{array}{c}\text { Correlation Coefficient } \\
\text { Sig. (2-tailed) } \\
\mathrm{N} \\
\end{array}$ & $\begin{array}{c}-, 055 \\
, 635 \\
76 \\
\end{array}$ & $\begin{array}{c}1,000 \\
\cdot \\
76 \\
\end{array}$ & $\begin{array}{c}-, 224 \\
, 052 \\
76 \\
\end{array}$ \\
\hline & $\begin{array}{c}\text { Telah } \\
\text { mendapatkan } \\
\text { kurikulum hukum } \\
\text { kesehatan }\end{array}$ & $\begin{array}{c}\text { Correlation Coefficient } \\
\text { Sig. (2-tailed) } \\
\mathrm{N}\end{array}$ & $\begin{array}{c}-, 279^{*} \\
, 015 \\
76\end{array}$ & $\begin{array}{c}-, 224 \\
, 052 \\
76\end{array}$ & $\begin{array}{c}1,000 \\
.\end{array}$ \\
\hline
\end{tabular}

*. Correlation is significant at the 0.05 level (2-tailed).

Tabel 6. Hubungan antara tingkat pengetahuan dengan angkatan dan yang telah melewati stase forensik

\begin{tabular}{|c|c|c|c|c|c|}
\hline & & & Angkatan & $\begin{array}{c}\text { Tingkat } \\
\text { Pengetahuan }\end{array}$ & $\begin{array}{l}\text { Telah } \\
\text { melewati } \\
\text { stase }\end{array}$ \\
\hline \multirow[t]{9}{*}{$\begin{array}{l}\text { Spearman's } \\
\text { rho }\end{array}$} & \multirow[t]{3}{*}{ Angkatan } & $\begin{array}{l}\text { Correlation } \\
\text { Coefficient }\end{array}$ & 1,000 & & \\
\hline & & Sig. (2-tailed) & & ,635 & ,015 \\
\hline & & $\mathrm{N}$ & 76 & 76 & 76 \\
\hline & \multirow[t]{3}{*}{$\begin{array}{l}\text { Tingkat } \\
\text { Pengetahuan }\end{array}$} & $\begin{array}{l}\text { Correlation } \\
\text { Coefficient }\end{array}$ & & 1,000 & \\
\hline & & Sig. (2-tailed) & ,635 & . &, 052 \\
\hline & & $\mathrm{N}$ & 76 & 76 & 76 \\
\hline & \multirow{3}{*}{$\begin{array}{l}\text { Telah } \\
\text { mendapatkan } \\
\text { kurikulum } \\
\text { hukum kesehatan }\end{array}$} & $\begin{array}{l}\text { Correlation } \\
\text { Coefficient }\end{array}$ &,$- 279^{*}$ &,- 224 & \multirow[t]{3}{*}{1,000} \\
\hline & & Sig. (2-tailed) &, 015 &, 052 & \\
\hline & & $\mathrm{N}$ & 76 & 76 & \\
\hline
\end{tabular}

*. Correlation is significant at the 0.05 level (2-tailed). 
Menurut Sunarwo (2006) koefisien korelasi dilihat dalam tingkatannya yaitu :

\begin{tabular}{|c|c|}
\hline $\begin{array}{c}\text { Interval } \\
\text { Koefisien }\end{array}$ & $\begin{array}{c}\text { Tingkat } \\
\text { Hubungan }\end{array}$ \\
\hline 0,00 & $\begin{array}{c}\text { Tidak ada } \\
\text { korelasi }\end{array}$ \\
\hline$>0-0,25$ & $\begin{array}{c}\text { Korelasi } \\
\text { Rendah }\end{array}$ \\
\hline$>0,25-0,50$ & Cukup \\
\hline $0,51-0,75$ & Kuat \\
\hline $0,76-0,99$ & Sangat Kuat \\
\hline 1 & Sempurna \\
\hline
\end{tabular}

Pada tabel hubungan tersebut menunjukkan hubungan antara angkatan dan mahasiswa yang telah melewati stase forensik dengan tingkat pengetahuan memiliki hubungan yang rendah dan dari signifikan >0,05 maka hubungan antara kedua variabel tidak signifikan, atau kurang bermakna. Variabel berikutnya menghubungkan antara mahasiswa kepanitraan yang sudah melewati forensik dan yang belum melewati forensik. Hasil tabel tersebut menunjukan terdapat tidka bermakna antara kedua variabel, korelasi yang didapatkan merupakan hubugan korelasi rendah. Nilai korelasi spearman's sebesar kedua variabel menunjukkan korelasi negatif, atau berbanding terbalik.

Tabel 7. Hubungan antara pengetahuan Mahasiswa Kepaniteraan berdasarkan angkatan

\begin{tabular}{|rll|r|r|}
\hline & & \multicolumn{2}{c|}{$\begin{array}{c}\text { Tingkat } \\
\text { Pengetahuan }\end{array}$} & Angkatan \\
\hline Spearman's rho & Tingkat Pengetahuan & Correlation Coefficient & 1,000 &, $258^{*}$ \\
& & Sig. (2-tailed) &. &, 025 \\
& $\mathrm{~N}$ & 76 & 76 \\
\cline { 2 - 5 } & Angkatan & Correlation Coefficient &, $258^{*}$ & 1,000 \\
& Sig. (2-tailed) &, 025 &. \\
& $\mathrm{~N}$ & 76 & 76 \\
\hline
\end{tabular}

*. Correlation is significant at the 0.05 level (2-tailed).

Menurut Sugiono koefisien korelasi dilihat dalam tingkatannya yaitu :

\begin{tabular}{|c|c|}
\hline $\begin{array}{c}\text { Interval } \\
\text { Koefisien }\end{array}$ & $\begin{array}{c}\text { Tingkat } \\
\text { Hubungan }\end{array}$ \\
\hline $0,00-0.199$ & Sangat rendah \\
\hline $0,20-0,399$ & Rendah \\
\hline $0,40-0,599$ & Sedang \\
\hline $0,60-0,799$ & Kuat \\
\hline $0,80-1,000$ & Sangat Kuat \\
\hline
\end{tabular}

Pada tabel hubungan tersebut menunjukkan hubungan yang rendah dan dari signifikan $>0,05$ maka hubungan antara kedua variabel tidak signifikan, atau kurang bermakna

Berikutnya adalah hubungan antara pengetahuan mahasiswa kepaniteraan tentang pengertian malpraktik dan sudah atau belumnya mendapatkan kurikulum hukum kesehatan stase forensik. 
Tabel 8. Hubungan antara mahasiswa yang sudah melewati stase forensik dengan pengetahuan tentang malpraktik kedokteran

\begin{tabular}{|lll|r|r|}
\hline & & & Tingkat \\
Pengetahuan & \multicolumn{2}{c|}{$\begin{array}{c}\text { Telah melewati } \\
\text { stase }\end{array}$} \\
\hline Spearman's rho & Tingkat Pengetahuan & Correlation Coefficient & 1,000 &,$- 573^{* *}$ \\
& & Sig. (2-tailed) & $\cdot 000$ \\
& & $\mathrm{~N}$ & 76 & 76 \\
\cline { 2 - 5 } & Telah mendapatkan & Correlation Coefficient &,$- 573^{* *}$ & 1,000 \\
& kurikulum hukum & Sig. (2-tailed) &, 000 &. \\
& $\mathrm{~N}$ & 76 & 76 \\
\hline
\end{tabular}

**. Correlation is significant at the 0.01 level (2-tailed).

Variabel berikutnya menghubungkan antara mahasiswa kepanitraan yang sudah melewati forensik dan yang belum melewati forensik. Hasil tabel tersebut menunjukan terdapat korelasi bermakna antara kedua variabel. Nilai corelassi spearman's sebesar -,573 menunjukkan korelasi negatif.

\section{SIMPULAN}

Analisis data pertama maka yang terbukti adalah Hipotesis 0 yang merupakan terdapat hubungan signifikan antara pengetahuan mengenai malpraktik kedokteran dengan mahasiswa yang telah melewati stase forensik. Korelasi memiliki korelasi positif rendah yakni berbanding lurus dengan kenaikan jumlah.

Analisis data kedua tentang pengetahuan mengenai prosedur pelaporan Hipotesis alternatif adalah benar. Hal ini ditunjukkan karena tidak bermakna karena $p>0,05$. korelasi yang yang sudah dilakukan merupakan hubungan korelasi terbalik atau negatif.

\section{DAFTAR PUSTAKA}

${ }^{1}$ Kitab Undang-Undang Hukum Pidana. http://hukum.unsrat.ac.id/uu/kuh pidana.htm. 2011. diakses 26 Juli

\section{4}

${ }^{2}$ Nur A. 2015. Gambaran Laporan Aduan Dugaan Pelanggaran Etik Kedokteran Majelis Kehormatan Etik Kedokteran Wilayah Jawa Barat Periode tahun 2009-2014. Cimahi. Fakultas Kedokteran Universitas Jenderal Achmad Yani.

${ }^{3}$ Siswanti S. 2013. Etika dan Hukum Kesehatan dalam Perspektif Undang-undang Kesehatan. Jakarta: Raja Grafindo Persada

${ }^{4}$ Komalawati V. 1989. Hukum dan Etika dalam Praktek Dokter. Bandung: Sinar Pustaka Harapan

5Ramdhana D. 1999. Penuntun Kuliah Kedokteran dan Hukum Kesehatan Kedokteran. Jakarta: ECG

${ }^{6}$ Republik Indonesia.Undang-undang No. 29 Tahun 2004 tentang Praktik Kedokteran. Jakarta: Sekretariat Negara.

${ }^{7}$ Ikatan Dokter Indonesia. Kode Etik Kedokteran Indonesia. IDI. Jakarta. 2012

${ }^{8}$ Nurduha OU. 2015. Gambaran Pengetahuan dan Sikap Keluarga Pasien Mengenai Persetujuan Tindakan Medis pada Pasien 
Tidak Kompeten di Rumah Sakit

Dustira. Cimahi: Fakultas Kedokteran Universitas Jenderal Achmad Yani.

${ }^{9}$ Sholihin B. Kami Tidak Mengenal Istilah Malpraktek. https://nasional.tempo.co/.2013. diakses tanggal 23 Desember 2013

${ }^{10}$ Chazawi A. 2016. Standar Profesi, Standar Prosedur, Inforemed Consent, dan Hubungannya dengan Malpraktik Kedokteran. Jakarta: Sinar Grafika

${ }^{11}$ Badan Pusat Statistik. Survei Mengenai Media. BPS. Jakarta.2013.

${ }^{12}$ Departemen Pendidikan Nasional. Kamus Besar Bahasa Indonesia $3^{\text {rd }}$ ed. DEPDIKNAS. Jakarta. 2001.

${ }^{13}$ Notoatmodjo, S. 2005. Promosi Kesehatan. Jakarta: Rineka Cipta

${ }^{14}$ Sunaryo. 2004. Psikologi untuk Keperawatan. Jakarta: ECG

${ }^{15}$ Ratman D. 2014. Aspek Hukum Penyelenggaraan Praktek Kedokteran dan Malpraktek Medik. Bandung: CV. Keni Media

${ }^{16}$ Hendrik. 2001. Etika dan Hukum Kesehatan. Jakarta: ECG

${ }^{17}$ Bhekti S. 2013. Panduan Yuridhis Penyelenggaraan Praktik Kedokteran. Jakarta: Dunia Cerdas

${ }^{18}$ Ratman. 2012. Mediasi Nonligigasi terhadap Sengketa Medik engan Konsep Win-win Solution. Jakarta: PT Elek komputindo

${ }^{19}$ Guwandi J, 2007.Hukum Medik (Medical Law). Jakarta: Balai Penerbit FKUI

${ }^{20}$ Moeljanto. 2011. Kitab undang-undang hukum Pidana. Jakarta: bumi aksara;

${ }^{21}$ Syahrial D, 2005. Praktik Kedokteran dan Aplikasinya. Jakarta: Niaga swadaya.

${ }^{22}$ Chawazi A. 2007. Malpraktik Kedokteran. Malang: Bayumedia Publising

${ }^{23}$ Dibroto SS. KUHP dan KUHAP dilengkapi dengan Yurisprodensi Mahkamah Agung dan Hoge Raad. Jakarta:PT raja grafindo persada; 1994.

${ }^{24}$ Kitab Undang-undang Hukum Pidana edisi lengkap. Ed 3. Jakarta: Triniti Optima Media; 2007.

${ }^{25}$ Republik Indonesia. Undang-Undang No. 23 tahun 1992 Tentang Kesehatan. Jakarta: Sekretariat Negara;1992.

${ }^{26}$ Sokanto S. 1990. Segi-segi Hukum Hak dan Kewajiban Pasien. Jakarta: Mandar Maju

${ }^{27}$ Putra KR. 2012.Peran Ikatan Dokter Indonesia Dalam Penyelesaian Kasus Sengketa Medik di POLDA DIY. Yogyakarta: Fakultas Kedokteran Universitas Gadjah Mada.

${ }^{28}$ Konsil Kedokteran Indonesia. Peraturan Konsil kedokteran Indonesia No. 15 tahun 2006 tentang Organisasi dan Tatakerja Majelis Kehormatan Disiplin Kedokteran Indonesia dan Majelis Kehormatan Disiplin Kedokteran Indonesia di Tingkat Provinsi. KKI. Jakarta. 2006.

${ }^{29}$ Fakultas Kedokteran Universitas Lampung. Modul Pedoman Majelis Kehormatan Etik Kedokteran. http://fk.unila.ac.id/. 2016. [bulan Juli 2016]

${ }^{30}$ Ikatan Dokter Indonesia. Pedoman Organisasi dan Tatalaksana kerja Majelis Kehormatan Etik Kedokteran. Jakarta. 2008.

${ }^{31}$ Pengurus Besar Ikatan Dokter Indonesia. Kode etik kedokteran Indonesia. PBIDI. Jakarta. 2012. 
${ }^{32}$ Dahlan MS. 2010. Besar Sampel dan Cara Pengambilan Sampel dalam Penelitian Kedokteran dan Kesehatan. Jakarta: Salemba Medika.

${ }^{33}$ Dahlan MS. 2014. Statistik untuk Kedokteran dan Kesehatan deskriptif, bivariat dan multivariat. Jakarta:

Epidemiologi Indonesia. 